\title{
Research on Using Mixed Refrigerant to Replace the Traditional Refrigerant in Air Source Heat Pump Water Heater
}

\author{
Cheng $\mathrm{Yu}^{1, \mathrm{a}}$, "Fang Wang ${ }^{2, \mathrm{~b}}$,Hai-Xiang Fang ${ }^{3, \mathrm{c}}$, \\ 1,2,3 University of Shanghai for Science and Technology, Shanghai 200093, China

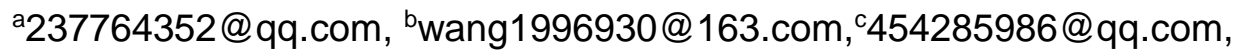 \\ "Corresponding author
}

Keywords: R1234ze/R32 mixed refrigerant, Air source heat pump water heater, Performance test

\begin{abstract}
In this paper, R1234ze and R32 will be mixed in 2 different proportions. And it will be used to make comparative experiments with a traditional mixed refrigerant (R410a) in air source heat pump water heater. By analysis the data of experiments some intuitive charts will be made. The results show that the R1234ze/R32 mixed refrigerant has better performance. It also provides a possibility of using a new mixed refrigerant to replace the traditional one.
\end{abstract}

\section{Introduction}

In this paper, an air source heat pump water heater will be used as the experimental device. It has the similar operation principle of heat pump air conditioner. They all use outdoor low grade heat as resource to provide heat water or heat air by condenser and heat exchanger[1]. Air source heat pump water heater also has a lot of advantages such as high efficiency, energy saving, wide application scope and so on. But in recent years, along with strengthening of people's environment protection awareness, air source heat pump water heater can no longer meet our requirements. Nowadays air source heat pump water heater use R410a (or other pure refrigerants) as it's refrigerant. Despite the fact that R410a is a very efficient and environmental refrigerant, it also can be replaced by a better and cheaper mixed refrigerant. With this requirement R1234ze come in to our view. R1234ze is an environment friendly refrigerant with low price. Its ODP is 0 and GWP is 6. S. Grauso and J.R. Thome[2] have done the research on the flow characteristics, heat transfer and pressure drop characteristics of the R1234ze in refrigeration system. Koyama[3] has made experiments to research the best charge of R1234ze in air source heat pump water heater. Although the working efficiency of R1234ze is not as good as R410a, it can be optimized by adding R32 on it. In this research, we are going to talk about R1234ze/R32 mixed refrigerant. 5 comparative experiments will be made between R1234ze/R32 mixed refrigerant and R410a in different condition[4]. Date shows that in the same condition compressor has lower suction and discharge pressure when using R1234ze/R32 mixed refrigerant than it's using R410a. And R1234ze/R32 mixed refrigerant can also increase the system COP. All of these were worth using for reference for system optimization.

\section{Principle of Air Source Heat Pump Water Heater Experiment System}

3 kinds of mixed refrigerants were used to carry out experiments in the same heat pump water heater cycle under different working conditions. The principle of air source heat pump water heater can be shown in Figure 1. (1) low temperature and high pressure liquid refrigerant will depressure after through the throttling expansion mechanism. Than the refrigerant will absorb a large amount of heat Q1 from the air when it through heat exchange and air entering the evaporator; (2) After evaporating the refrigerant enters the compressor in the form of gas. The compressor will compress the refrigerant vapor into high temperature and high pressure. At that moment, there are two parts of 
heat in the refrigerant vapor, Q1 and Q2. Q1 is from outside environment. Q2 is from the works made by compressor; (3) High temperature and high pressure refrigerant vapor goes into the heat exchanger. In heat exchanger, the heat $(\mathrm{Q} 1+\mathrm{Q} 2)$ will be released to water in the water tank which provides heat water to the user; (4) After all refrigerant became liquid again. Those liquid refrigerant goes into the expansion mechanism of throttling. Like this refrigerant move in a circle[5,6].

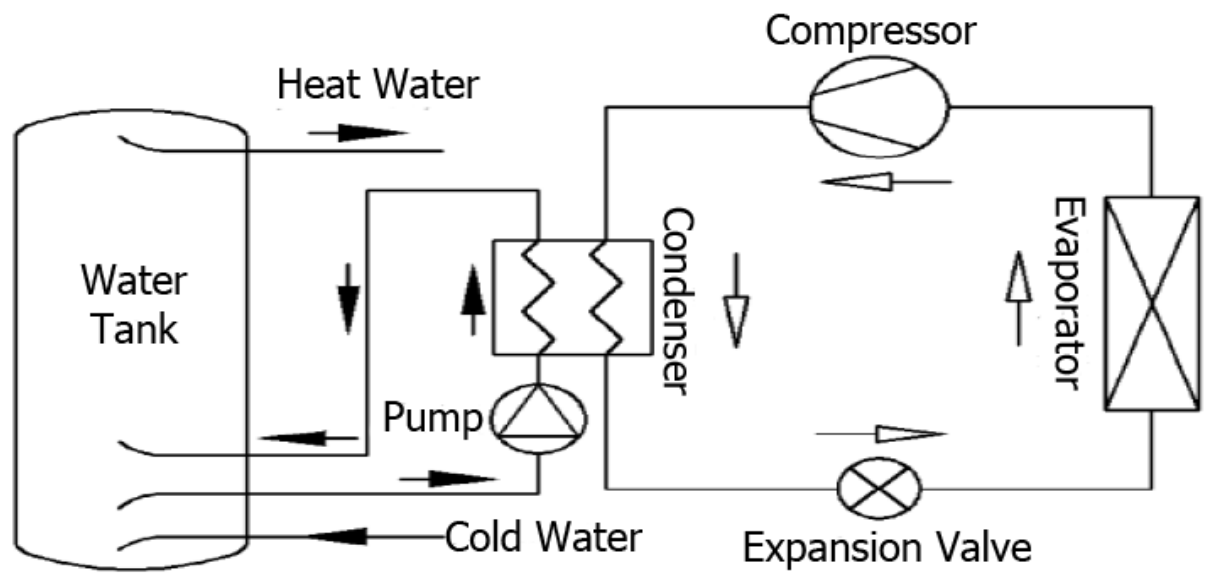

Figure 1. Air Source Heat Pump Water Heater System

\section{Experimental Device and Experimental Method}

Some improvements have been made basis on traditional air source heat pump water heater system and we also redesign the system to meet experimental requirements. Finally, a two stage compression air source heat pump hot water system with an enhanced vapor injection was selected to be our experiment device. The experimental principle as shown in Figure 2.

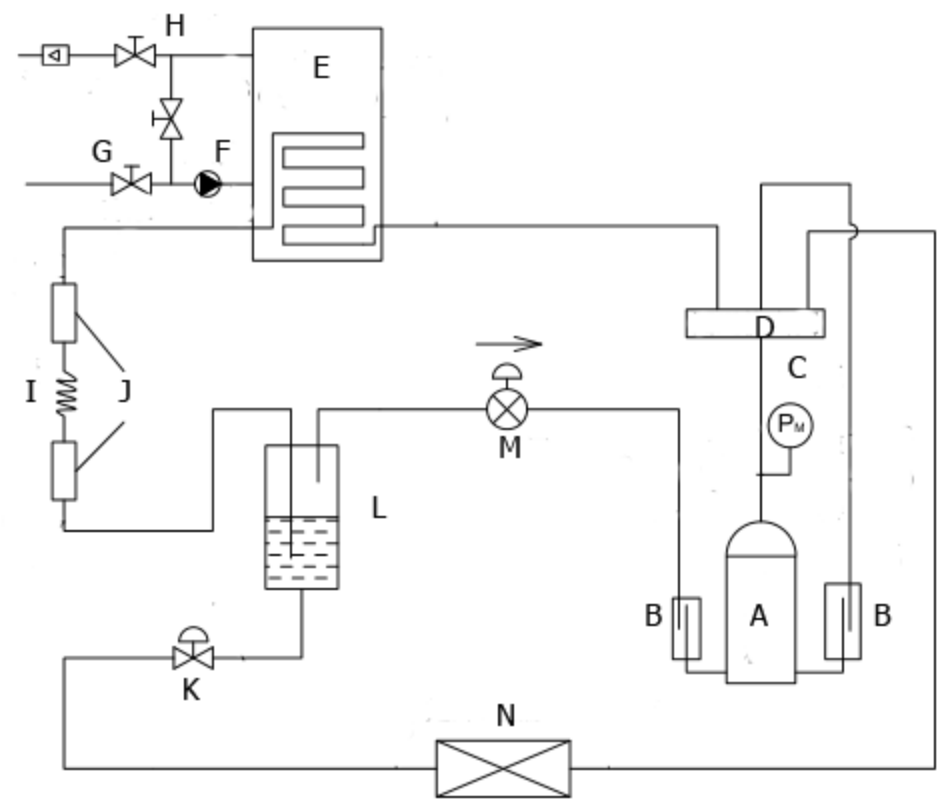
A compressor
B gas-liquid separator
C pressure controller
D four-way reversing valve
E water tank
F pump
G cold water
$\mathrm{H}$ hot water
I capillary
$\mathrm{J}$ filter
$\mathrm{K}$ electronic expansion valve
L flash evaporator
M electromagnetic valve
$\mathrm{N}$ evaporator

Figure 2. Schematic Diagram of Experimental Device

Three kinds of refrigerant will be used to make experiments, a mixed refrigerant contain $70 \% \mathrm{R} 32$ and 30\% R1234ze (Hereinafter referred to as refrigerant X), another mixed refrigerant contain 60\% R32 and 40\% R1234ze (Hereinafter referred to as refrigerant Y), and R410a. 5 test conditions were selected according to GB/T 2313-2008 and those 5 test conditions have been listed in table 1 . 
Table 1. Experiment Conditions

\begin{tabular}{ccccc} 
Test & \multicolumn{2}{c}{ Air Side } & \multicolumn{2}{c}{ Water side } \\
Condition & $\begin{array}{c}\text { Dry-Bulb } \\
\text { temperature/C }\end{array}$ & $\begin{array}{c}\mathrm{C}^{\circ} \\
\text { temperature } / C^{\circ}\end{array}$ & $\begin{array}{c}\text { Inlet water } \\
\text { temperature } / C^{\circ}\end{array}$ & $\begin{array}{c}\text { Out water } \\
\text { temperature } / C^{\circ}\end{array}$ \\
Condition 1 & 35 & 24 & 20 & 55 \\
Condition 2 & 20 & 15 & 15 & 55 \\
Condition 3 & 7 & 6 & 9 & 55 \\
Condition 4 & 2 & 1 & 9 & 55 \\
Condition 5 & -7 & -8 & 9 & 55
\end{tabular}

\section{Experimental Data Analysis}

The change of refrigerant in air source heat pump water heater system will make great influence on each state parameters of the system. Such as suction and discharge temperature(pressure)of the compressor, power consumption of the system, heating time of hot water under the same working condition, performance coefficient COP of the system and so on.

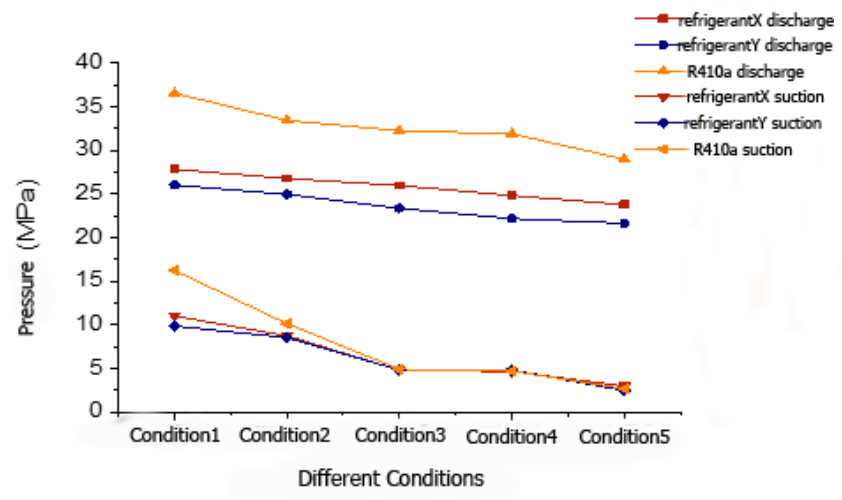

Figures 3.

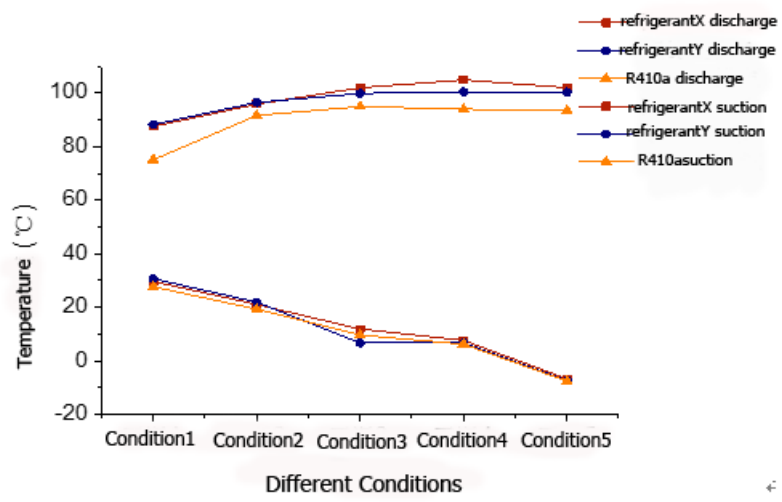

Figures 4.

Figure 3 shows that under the same condition, the exhaust temperature of refrigerant $X$ and refrigerant $\mathrm{Y}$ are all higher than the exhaust temperature in R410a system. It can be seen that when R32 and R1234ez were mixed as a mixed refrigerant, the more R32 we used means the higher exhaust temperature of the system. We also can see that with the decrease of environment temperature, exhaust temperature is gradually increased and the suction temperature gradually decreased. The reason of this phenomenon is that with the decrease of ambient temperature, the evaporation temperature is reduced and the evaporator heat transfer effect becomes poorer in order to obtain heat from in low temperature environment, the throttle valve opening decreases, the refrigerant flow decreases and the inspiratory volume of compressor is increased which result in the increase exhaust temperature of the compressor.

Figure 5 shows that under the same conditions, the exhaust pressure of refrigerant $X$ and refrigerant $\mathrm{Y}$ are all lower than the exhaust pressure in R410a system, which means the lower R1234ze content in a mixed refrigerant, the lower suction and discharge pressure a system have. This is because the R1234ze refrigerant pressure is low. With the decrease of working temperature, suction and discharge pressure of three kinds of refrigeration system was decreased and the compression ratio increased with the decreasing temperature. 


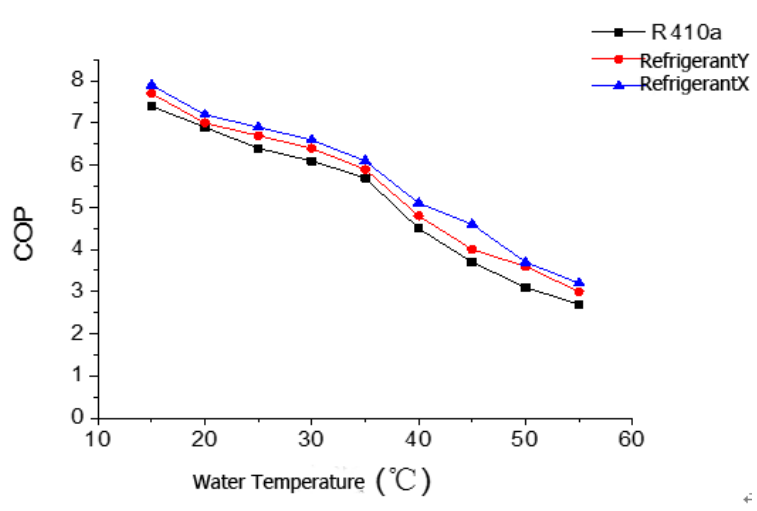

Figure 5.

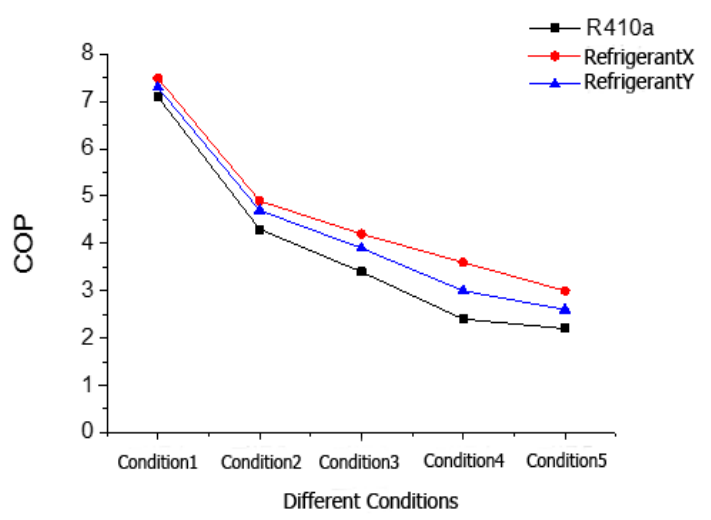

Figure 6.

Figure 5 shows that with the increase temperature of heated water, the COP of system is gradually decreased. This is because that at the beginning the water in water tank is cold and the temperature of refrigerant is very high so they can exchange heat very efficient in the condenser. But the temperature different between water and refrigerant is becoming small which will reduce the heat exchange efficiency and the COP of the system. At the same time, in order to maintain the normal temperature difference, the compressor consumes more power to compress the refrigerant gas which cause the system power consumption increased and COP decreased too.

As it can be seen from Figure 6, the COP of the heat pump system decreases with the decrease of the ambient temperature. And in the same condition, the heating coefficient of mixed refrigerant in heat pump system is better than which in the R410a system. And in mixed refrigerant more R32 content means the higher COP in system, it can be seen that the mixed refrigerant has certain advantages compared with R410a.

\section{Conclusions}

After analyzing the experimental data, we can conclude that:

1, Under the same operating conditions, the mixture of R32 and R1234ze mixed with 7:3 has higher COP, which shows that the COP of the mixed refrigerant increases with the increase of R32 content. 2, Under different operating conditions, COP will decrease with the decrease of the working environment temperature, and the increase of the preset water temperature will decrease the COP.

3 , It is proved that the mixed refrigerant composed of R32 and R1234ze can be used as a substitute for traditional refrigerants, and it has a great development prospect.

\section{Acknowledgements}

This work wad financially supported by the 2016 Innovation Program of College Student on Shanghai Higher Education Commission.

\section{References}

[1] Si-Yu Li, Hai-Xiang Fang, Yuan Fan. Performance Experimental Study of Environment Friendly Refrigerant R32 Enhanced Vapor Injection Heat Pump Water Heater. ECCSD 2016 (May) 130-134.

[2] S. Grauso, R. Mastrullo. Flow pattern map, heat transfer and pressure drops during evaporation of R-1234ze(E) and R134a in a horizontal, circular smooth tube: Experiments and assessment of predictive methods [J]. International Journal of Refrigeration. 2013, 36(2):578-491.

[3] Koyama S, Kondou C, Mishima, F. Condensation and Evaporation of Low GWP Refrigerant Mixture R32/R1234ze(E) in Horizontal Microfin Tubes [C]. // Transactions of the Japan Society 
of Refrigerating and Air Conditioning Engineers, Japan: Japan Society of Refrigerating and Air Conditioning Engineers, 2013:401-411.

[4] Fang Li, Chao-Dong Zhou, Xin Wu. Research on Environmental Friendly Refrigerant Heat Pump Water Heater Based on Enhanced Vapor Injection.ECCSD2016 (May)55-59.

[5] C. Aprea, R. Mastrullo, C. Renno. An Analysis of the Performances of a Vapour Compression, Plant Working both as a Water Chiller and a Heat Pump using R22 and R417A.2014(24)487-499.

[6] Feng-Hao Wang, Zhi-Hua Wang, Yu-Xin Zheng, Ji-Bo Hao. Research Progress and Prospect of Air Source Heat Pump in Low Temperature Environment Journal of Refrigeration 2013(05)47-54. 